\title{
Impact of Distributed Generation on Reliability of Distribution System
}

\author{
Basudev Das1 \& Dr Bimal C Deka2 \\ 1Assam Engineering Institute, Chanmari, Guwahati-781003, Assam, India \\ 2Assam Engineering College, Jalukbari, Guwahati-781013, Assam, India
}

\begin{abstract}
Distributed Generation (DG) serves a customer on-site and it provides support to a distribution network. DG is connected at distribution level voltage. The resources used for DG are preferably renewable resources. DG may be used as a standby unit. It helps to improve the reliability of the distribution network. The reliability improvement will be maximum if $D G$ unit is located optimally in the distribution network. Reliability improvements due to DG connection with the distribution network also depends on method of installation of disconnects at sections forming a junction in the distribution network. After penetration of $D G$, the passive distribution system becomes an active system. Therefore, it is essential for the planners to study the impact of $D G$ on distribution system reliability. The aim of the paper is to study the effect of $D G$ on reliability of distribution system.
\end{abstract}

Keywords: Distributed generation, distribution system, active network, reliability indices, distributed energy resources, optimal location

\section{Introduction}

Conventionally, power is generated by centrally located power plants. The efficiency of the power station is in the range of $28 \%$ to $35 \%$ [1]. The distance between centrally locate plant and consumer is very large. The power is transmitted to the load centre through interconnected transmission line. From the load centre, it is distributed amongst the consumers through interconnected distribution lines. Different types of problems develop due to the large distance between generating plant and consumers. There are also many technical problems and financial constraints in building new transmission line to transmit power from the power plants to the load centre to meet the increased demand. Though power transfer capacity of the existing line can be increased using FACTS, but there is a limitation. Production of green house gases is another problem with centrally located plants. Moreover, fossil fuels have been the main sources of electrical energy so far. If alternative arrangement is not made in case of fuel, the world will have to face severe problems in the near future.

Distributed Generation (DG) will play an important role in solving such energy problems. It helps to reduce environmental pollution by replacing fossil fuel through renewable energy sources. It also helps to improve the reliability of the system. Both renewable and non renewable technologies can be used for DG. Renewable technologies include solar, photovoltaic, wind, geothermal, tidal, micro-hydel, energy from municipal waste and biomass generation etc. Non-renewable technologies include internal combustion engine, combined engine, combustion turbine, fuel cell, etc.

The renewable energy sources are having smaller energy density and intermittent behavior. For this reason, the distributed generation plants based on these sources are smaller and geographically wide spread. These distributed resources are demand and supply side resources that can be deployed throughout an electric distribution system (as distinguished from the transmission system) to meet the energy and reliability needs of the customer served by the system. Distribution resources can be installed on either the customer side or the utility side of the meter [2].

A methodology is proposed in [3] for optimal allocation of DG on distribution network with respect to all of the relevant technical constraints. In [4], the authors studied the impact of DG on distribution system with different sizes of DG at different location of the system. In [5], the authors described a methodology to estimate the impact of DG on the reliability indices considering the isolated and interconnected operation of DG. The authors of [6] discussed two criteria--- one is to maximize the reliability improvement and other is to minimize the power loss in the system for the optimal placement of DG for time varying load. In [7], it is showed that the reliability of the distributed resources unit during isolated operation has a large impact on the resulting reliability. In [8], the authors proposed a method for optimal DG unit allocation and sizing in order minimize the electrical losses and cost of DG installation. In [9], the authors described that the existing distribution system will be the best if DG is allocated optimally and the development from passive to active is planned optimally with all relevant consideration taken account of. In [10], the authors showed that the reliability improvement 
will be maximum if the location of DG is such that it provides maximum access to the customers in terms of customers numbers, overall demand and priority of customer.

In this paper, customer related reliability indices of a radial distribution system with and without DG are evaluated by using the load point indices. One new method is proposed to find out the load point indices. The DG units are used as stand by or for isolated operations. The load point indices and customer related indices are evaluated with proper and improper disconnects at sections forming a junction.

\section{Distribution System Reliability:}

Power system reliability has two aspects: system adequacy and system security [11]. The present work is concerned only with system adequacy. The three functional zones: generation, transmission and distribution are combined to give three hierarchical levels: HL-I, HL-II and HL-III for reliability evaluation of power systems. HL-I includes only the generation facilities. HL-II includes both generation and transmission facilities. HL-III includes all three functional zones.

Reliability analysis of HL-III is most complex because it includes all three functional zones of power system. For this reason the distribution functional zone is analyzed as separate entity. The objective of the HLIII study is to obtain suitable reliability indices at consumer load point.

The three basic customer related indices for reliability analysis of distribution system are: rate (or frequency) of failure $\lambda_{\mathrm{s}}$, average outage time (or average duration of failure) $\mathrm{r}_{\mathrm{s}}$ and average annual outage time Us [11].

$$
\begin{aligned}
& \lambda_{\mathrm{s}}=\sum \lambda_{\mathrm{i}} \\
& \mathrm{U}_{\mathrm{s}}=\sum \lambda_{\mathrm{i}} \mathrm{r}_{\mathrm{i}} \\
& \mathrm{r}_{\mathrm{s}}=\mathrm{U}_{\mathrm{s}} / \lambda_{\mathrm{s}}
\end{aligned}
$$

where $\lambda_{i}$ is the failure rate of load point $i$ and $r_{i}$ is the average outage time of load point $i$

The load point failure $\lambda_{\mathrm{i}}$ can be determined using equation (1).

$$
\begin{aligned}
& \lambda_{\mathrm{i}}=\mathrm{rL}_{\mathrm{T}}+\mathrm{r}_{\mathrm{i}}^{\prime} \\
& \mathrm{r}=\text { Failure rate } / \mathrm{m} \text { of the section } \\
& \mathrm{L}_{\mathrm{T}}=\text { Total length of all sections in meter } \\
& \mathrm{r}_{\mathrm{i}}^{\prime}=\text { Failure of lateral connected to load point } \mathrm{i} \\
& \lambda_{\mathrm{i}}=\text { Failure rate at load point } \mathrm{i}
\end{aligned}
$$

The annual outage time for the load point $i$ can be calculated by adding the affect of outage of all sections on that point plus the outage time of lateral connected to that point using equation (2)

$$
\begin{aligned}
& \mathrm{U}_{\mathrm{i}}=\mathrm{r} \mathrm{L}_{\mathrm{e}} \mathrm{R}+\mathrm{r}\left(\mathrm{L}_{\mathrm{T}}-\mathrm{L}_{\mathrm{e}}\right) \mathrm{R}^{\prime}+\mathrm{r}_{\mathrm{i}}^{\prime} \mathrm{r}^{\prime \prime} \\
& \mathrm{r}=\text { Failure rate } / \mathrm{m} \text { of the section } \\
& \mathrm{L}_{\mathrm{T}}=\text { Total length of all sections in meter } \\
& \mathrm{L}_{\mathrm{e}}=\text { Length of affected section (sections) due to failure } \\
& \mathrm{R}=\text { Repairing time of the section } \\
& \mathrm{R}^{\prime}=\text { Switching time of the section } \\
& \mathrm{r}_{1}^{\prime}=\text { Failure of lateral connected to load point } \mathrm{i} \\
& \mathrm{r}^{\prime /}=\text { Repairing time of lateral }
\end{aligned}
$$

Average outage time (or average duration of failure) $r_{i}$ of load point $i$ can be calculated using $\lambda_{i}$ and $U_{i}$ by the equation (3)

$$
\mathrm{r}_{\mathrm{i}}=\mathrm{U}_{\mathrm{i}} / \lambda_{\mathrm{i}}
$$

The basic indices are important from an individual customer's point of view. But these do not provide the overall information of the system performance. There are some additional indices. These are calculated using those three basic indices, number of customers and load connected to each load point in the system. The customer related additional indices are [11]:

1. System Average interruption Frequency Index (SAIFI)

$$
\text { SAIFI }=\sum \lambda_{\mathrm{i}} \mathrm{N}_{\mathrm{i}} / \sum \mathrm{N}_{\mathrm{i}}
$$

2. System Average Interruption Duration Index (SAIDI)

$$
\text { SAIDI }=\sum \mathrm{U}_{\mathrm{i}} \mathrm{N}_{\mathrm{i}} / \sum \mathrm{N}_{\mathrm{i}}
$$

3. Customer Average Interruption Duration Index

$$
\text { CAIDI }=\sum \mathrm{U}_{\mathrm{i}} \mathrm{N}_{\mathrm{i}} / \sum \lambda_{\mathrm{i}} \mathrm{N}_{\mathrm{i}}
$$

4. Customer Average Interruption Frequency Index (CAIFI)

CAIFI= Total no of customer interruption /Total no of customer affected

5. Average Service Availability Index (ASAI)

$$
\text { ASAI }=\left(\sum \mathrm{N}_{\mathrm{i}^{*}} * 8760-\sum \mathrm{U}_{\mathrm{i}} \mathrm{N}_{\mathrm{i}}\right) / \sum \mathrm{N}_{\mathrm{i}^{*}} 8760
$$

6. Average Service Unavailability Index (ASUI)

$$
\text { ASUI }=1 \text { - ASAI }
$$

7. Energy Not Supplied (ENS)

$\mathrm{ENS}=\sum \mathrm{L}_{\mathrm{a}(\mathrm{i})} \mathrm{U}_{\mathrm{i}}$ 
8. Average Energy Not Supplied (AENS): $\mathrm{AENS}=\left(\sum \mathrm{L}_{\mathrm{a}(\mathrm{i})} \mathrm{U}_{\mathrm{i}}\right) / \sum \mathrm{N}_{\mathrm{i}}$

Here, $\mathrm{N}_{\mathrm{i}}$ is the no of customers at load point $\mathrm{i}, \mathrm{U}_{\mathrm{i}}$ is the annual outage time at load point $\mathrm{i}$.

\section{DISTRIBUTED GENERATION}

Distributed generation plays an important role in improving the reliability of distribution system. Many definitions and terms are used to define distributed generation. In Anglo- Saxon countries, it is termed as "Embedded Generation ", in North America it is termed as "Dispersed Generation" and in Europe and other parts of Asia it is termed as "Decentralized Generation" [12].

The term "Embedded Generation" is used to mean the concept of generation embedded in the distribution network. The International Energy Agency (IEA) has defined the distributed generation as a generating plant serving a customer on-site or providing support to a distribution network, connected to the grid at distribution level voltage. It includes small (and micro) turbines, fuel cells and photovoltaic cells etc. The wind power generation is not included as it produced energy in wind firm. According to IEA Dispersed Generation is distributed generation plus wind power and other generation either connected to distribution network or completely independent of grid.

The concept of application of DG is new and there is an increasing trend of use of DG in power system. The use of DG in power distribution system is increasing with technological advancement. About $20 \%$ of all new on-line generating plant is of this type. The increasing trend is due to social concern, economical and environmental consideration, reducing reserve of fossil fuel, power system deregulation, improvement of reliability of the system etc. The main benefit and advantages of distributed generation are: improved supply reliability through generation diversity, greater individual and community control over energy sources, reduced dependence on a small number of large generators, reduced power losses, reduced green house gas emission in case of renewable energy sources etc.

The increasing penetration of DG in the power system is raising the technical problems such as voltage regulation, network protection etc. The technical problems to be addressed when connecting a DG with distribution network are: power flow, steady state voltage variation, network loss, power quality, fault level contribution, transient stability etc [13]. Penetration of DG changes the characteristics of the distribution network since it converts the passive network into active distribution network [14].

\section{IMPACT OF DISTRIBUTED GENERATION ON DISTRIBUTION SYSTEM RELIABILITY:}

The connection of DG to a distribution system helps to improve the reliability of the system. The use of the existing distribution system will be the best if DG is allocated optimally and if the development from passive to active is planned optimally with all relevant considerations taken into account. The reliability improvement will be maximum if the location of the DG is such that it provides maximum access to the customers in terms of customer numbers, overall demand and priority of customer. DG may be used as standby or backup source. When DG units are applied as standup units, only affect will be on outage duration and do not affect the interruption frequency, so SAIFI will be constant and indices (except SAIFI) are too sensitive to location, number and availability of DG units [15].

\section{Case Study}

A residential distribution network of Chandmari-Milonpur area in Guwahati, Assam is considered for reliability analysis. The single line diagram of the network is shown in Fig.1. The network is having three junction points- first junction is among the sections 2,3 and 17 , second junction is among the sections 17, 18 and 19 and the third is among the sections 9,10 and 12 .

A radial distributor consists of sections and lateral distributors. In this paper lateral distributors are considered with separate lateral protection for each lateral. Failure at all sections and lateral distributor connected to a load point has the contribution to the failure rate of that particular load point.

The reliability analysis is performed with and without DG under the following conditions:

i. With improper disconnects installed at sections forming a junctions

ii. With proper disconnects installed at sections forming a junction

\section{Following assumptions are made for reliability analysis:}

1. Disconnect installed at each section is $100 \%$ reliable. An appropriate disconnect operates in case of a fault in a section and isolates the faulty section with the next adjacent load point from the healthy sections

2. Separate fuse-gear is installed at each lateral. An appropriate fuse-gear blows in case of a fault on a lateral distributor. Fuse gears are $100 \%$ reliable

3. DGs can operate independently 
4. Only active power flow is considered. Affect of DG on voltage, frequency, harmonic, power factor, reactive power, flickering, losses are not considered

5. Whenever there is a fault in any section, the main breaker opens

6. Repairing time for section and the lateral are $4 \mathrm{hr}$ and $2 \mathrm{hr}$ respectively

7. Switching time for section and lateral is $0.5 \mathrm{hr}$

8. Failure rate for section is $0.0056 \mathrm{f} / \mathrm{m} \mathrm{yr}$

The following situations will arise with improper disconnects at sections forming the junctions as shown in Fig. 1:

1. When there is a fault at section 2 , then sections $3,7,18 \& 19$ are affected and require repairing time of 4 $\mathrm{hr}$

2. When there is a fault at section 3 then sections $2,17,18 \& 19$ are affected and require repairing time of $4 \mathrm{hr}$

3. For a fault at section 17 , sections $2,3,18 \& 19$ are affected

4. For a fault at section 19 , sections $2,3,17 \& 18$ are affected

5. When there is a fault at section 18 , then this section is only isolated from the system

6. In case of a fault at section 9 , sections $10 \& 12$ are affected

7. For a fault at section 10 , sections $9 \& 12$ are affected

8. In case of a fault at section 12 , sections $10 \& 12$ are affected

In case of proper connection of disconnects at sections, only the faulty section of the junction can be isolated from the system.

The reliability data are presented in Table 1, 2 and 3. Table 1 shows the length of sections, Table 2 shows the failure rate of laterals and Table 3 shows the load point capacities.

\section{Results:}

The system reliability indices are calculated for the system shown in Fig 1 using the reliability data presented in Table 1, 2 and 3. The calculations have been done with and without DG in the system considering proper and improper disconnects. The Table -4 shows the results. The results are discussed in two sections A and $\mathrm{B}$ without and with DG respectively.

\section{A. Calculation of reliability indices without DG:}

There is no any improvement of SAIFI with proper connection of disconnects at sections which form the junction. SAIFI can be improved by introducing auto switching system or proper protection system in some section. The failure rate at load points will be different in that case. From our study, it is found that failure rates at load points are different depending on the failure rate of lateral.

SAIDI is improved with the proper connection of disconnects at the sections even without DG. If disconnects are not properly connected at different sections which form a junction then failure at one section connecting a junction affects the other sections which form that junction. The improvement of SAIDI without DG from improper to proper disconnects is $13.7 \%$.

Proper connection of disconnects at sections also help to improve the CAIDI of the radial distribution system even without DG connection. This improvement is $15.6 \%$. ASAI improves from 0.99452 to 0.99527.

Proper connection of disconnects at sections helps to improve the availability. Thus it reduces the expected energy not serve (EENS). Without proper disconnects at junctions, EENS reduces from 226279.51 Kwh/yr to $196000 \mathrm{Kwh} / \mathrm{yr}$ and thus the improvement is $13.4 \%$.

Thus proper connection of disconnects at sections forming a junction plays an important role in improving the reliability of a distribution system even without connecting DG to the system.

\section{B. Calculation of reliability indices with DG:}

DG of capacity $5000 \mathrm{KW}$ is connected to the load points $\mathrm{X}, \mathrm{Y}$ and Z separately with improper and proper disconnects at section forming the junction. This capacity of $5000 \mathrm{KW}$ is sufficient for meeting the load demand of all load points.

SAIDI improvements between X \& Y, X \& Z and Y \& Z for improper disconnects are 5.4\%, 29.8\% and 25.8\% respectively and with proper disconnects $6.5 \%, 19.1 \%$ and $13.5 \%$ respectively. $\quad$ SAIDI improvements between proper and improper disconnect at junction for location of DG at X, Y and Z are 9.2\%, 8.1\% and $21.3 \%$ respectively.

CAIDI improvements between X \&Y, X \& Z and Y \& Z for improper disconnects are 4.3\%, 29.8\% and 26.68\% respectively and with proper disconnects $6.1 \%, 15.6 \%$ and $21.9 \%$ respectively.

CAIDI improvements for proper and improper disconnect at junction for location of $\mathrm{DG}$ at $\mathrm{X}, \mathrm{Y}$ and $\mathrm{Z}$ are $9.1 \%, 7.2 \%$ and $21.3 \%$ respectively. 
In case of EENS, improvements between X \& Y, X \& Z and Y \& Z for improper disconnects are 5.3\%, 29.7\% and $25.6 \%$ respectively and with proper disconnects $6.4 \%, 18.9 \%$ and $13.3 \%$ respectively. EENS improvement for proper and improper disconnects at junction for location of $\mathrm{DG}$ at $\mathrm{X}, \mathrm{Y}$ and $\mathrm{Z}$ are $9.2 \%, 8.2 \%$ and $21.2 \%$ respectively.

For both proper and improper disconnects at sections forming the junction, the location of DG is the best at X for the DG capacity of $5000 \mathrm{KW}$. But SAIDI, CAIDI and EENS are the lowest and ASAI is maximum for the location of $\mathrm{DG}$ at $\mathrm{X}$ with proper disconnects at sections forming the junction.

The above results of sections $A$ and $B$ are presented graphically in Fig. 2, 3, 4 and 5. The percentage improvement of SAIDI, CAIDI and EENS between X \& Y, X \& Z and Y \& Z respectively are also presented in Fig. 6, 7 and 8 .

\section{Conclusion:}

There are two basic groups of indices for reliability evaluation of distribution system. One of the groups includes the three basic load point indices: failure rate, outage duration and annual outage time. The other group contains system based indices such as SAIFI, SAIDI, CAIDI, EENS etc.

Application of DG plays an important role in increasing the reliability of distribution system. All additional indices except SAIFI have improved with the application of DG. SAIFI may increase if auto-switching or other protective devices are connected to the sections or laterals.

The reliability of the distribution system can be improved even without connecting DG if the disconnects are connected properly at sections forming a junction. But significant improvement is observed if DG is connected with the distribution system having properly connected disconnects at sections. The reliability improvement is maximum if the DG is connected at a location from where it can meet the highest load demand. In our study the best location of DG with proper disconnects is the point " $\mathrm{X}$ ".

\section{References:}

[1]. Willis, H. Lee, Scott, Walter G.: "Distributed Power Generation", Marcel Dekker, Inc., New York

[2]. Moskovitz, D.:"Profit and Progress through Distributed Resources", Regulatory Assistance Project, Maine, USA.

[3]. Keane, A., O' Malley, M.:"Optimal Allocation of Embedded Generation on Distribution Networks", IEEE Transaction on Power System, Vol. 20, No. 3, August 2005.

[4]. Waseem, I., Pipattanasomporn, M., Rahman, S.: "Reliability Benefits of Distributed Generation as a Backup Source", Power \& Energy Society General Meeting 2009, PES, ’09, IEEE.

[5]. Neto, A. C., da Silva, M. G., Rodrigues, A. B.: "Impact of Distributed Generation on Reliability Evaluation of Radial Distribution Systems Under Network Constraints", $9^{\text {th }}$ International Conference on Probabilistic Method Applied to Power Systems KTH, Stockholm, Sweden, June $11-15,2006$.

[6]. Zhu, D., Broadwater, Robert P., Tam, Kwa-Sur, Seguin R., Asgeirsson, H.: "Impact of DG Placement on Reliability and Efficiency With Time - Varying Loads", IEEE Transaction on Power Systems, VOL. 21, No. 1, February 2006.

[7]. Sun, Y., Bollen, M. H. J., Ault, G.: "Improving Distribution System By Means Of Distributed Generation", 19 ${ }^{\text {th }}$ International Conference on Electricity distribution, Vienna, 21 - 24 May 2007

[8]. Borges, Carmen L. T., Falcao, Djalma M.: "Optimal Distributed Generation Allocation for Reliability, Losses and Voltage Improvement", Electrical Power and Energy System 28 (2006) 413 - 420

[9]. Keane, A., O' Malley, M.: “Optimal Allocation of Embedded Generation on Distribution Networks", IEEE Transaction on Power System, Vol. 20, No. 3, August 2005.

[10]. Banerjee, B., Islam, Sayed M.: "Reliability Based Optimum Location of Distributed Generation", Electrical Power and Energy System, 33(2011), $1470-1478$.

[11]. Billinton, R., Allan, Ronald N.: "Reliability Evaluation of Power System", Plenum Press, New York.

[12]. Ackerman, Thomas: "Distributed resources and re-regulated electricity markets", Electric Power System research 77(2007) 11481159.

[13]. Deka, Bimal C., Das, Basudev: "Embedded Generation And Its Effect On Distribution System Reliability", October 2011 All India Seminar On Power System Management organized by The Institution of Engineers ( India ), Assam State Centre, Panbazar, Guwahati.

[14]. Jenkins, N., Allan, R., Crossley, P., Kirschen, D. and Strbac, G.: “Embedded Generation”, The Institution of Electrical Engineers, London.

[15]. Jahangir, P., Fotuhi- Firuzabad, M.: "Reliability Assessment of Distribution System with Distributed Generation", $2^{\text {nd }}$ IEEE International Conference on Power and Energy, December 1 - 3, 2008, Johor Baharu, Malaysia. 
Fig.1: Distribution System for study
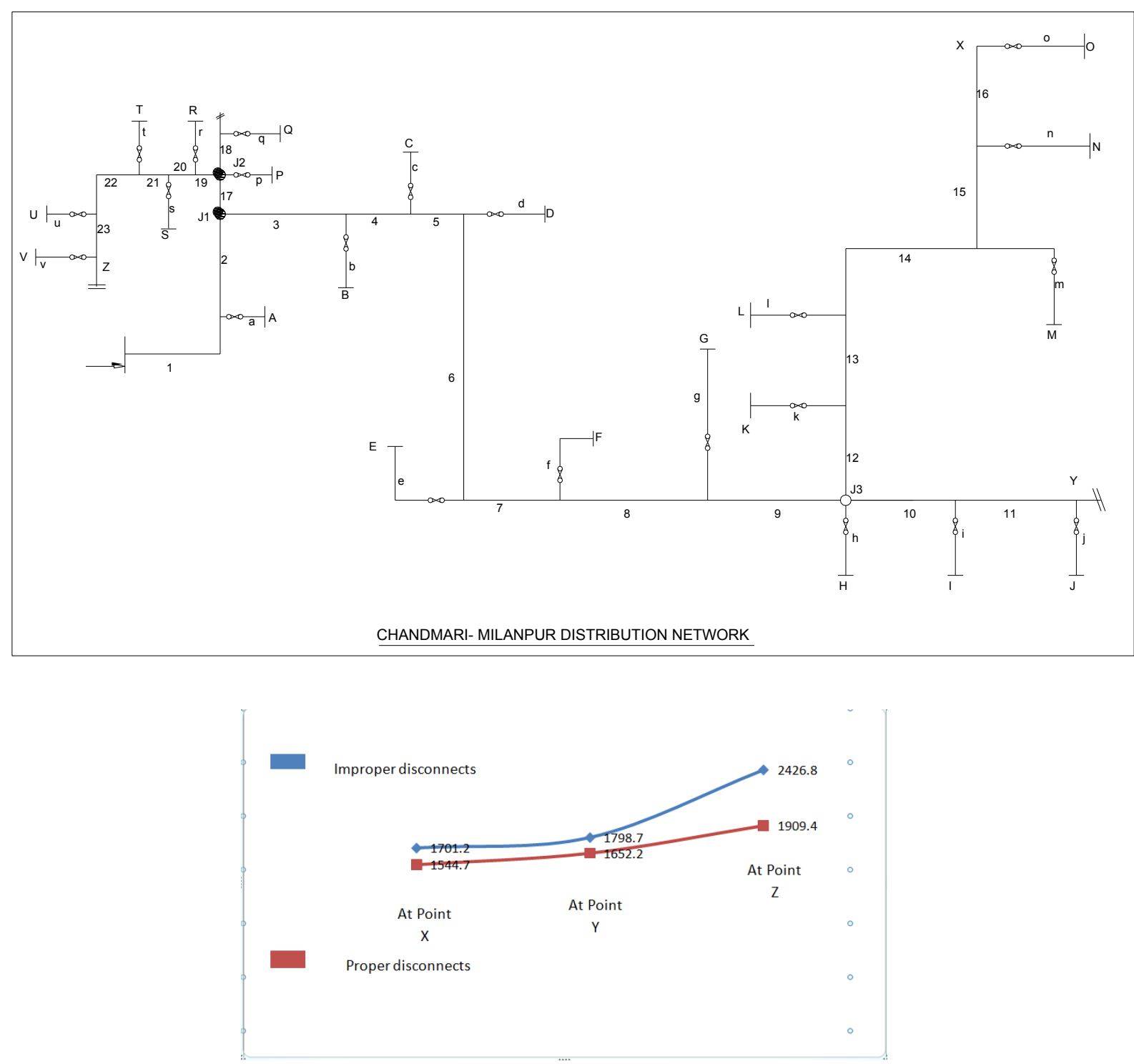

Fig. 2: SAIDI for $5000 \mathrm{KW}$ for proper and improper disconnects at Junctions

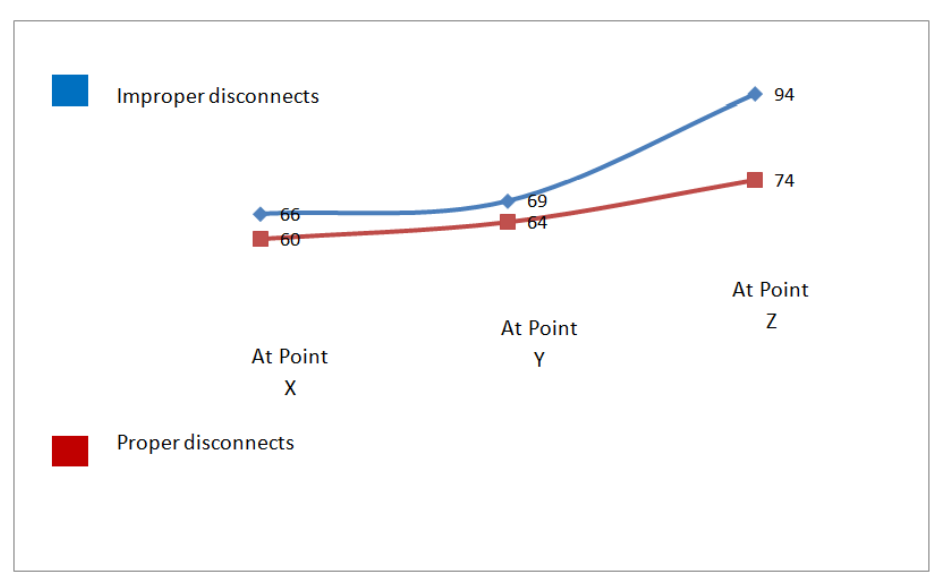

Fig. 3: CAIDI for $5000 \mathrm{KW}$ for proper and improper disconnects at Junctions 


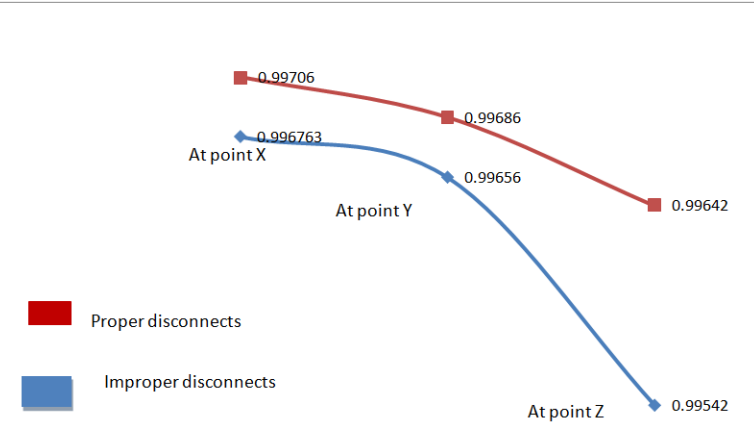

Fig 4: ASAI for $5000 \mathrm{KW}$ for proper and improper disconnects at junctions

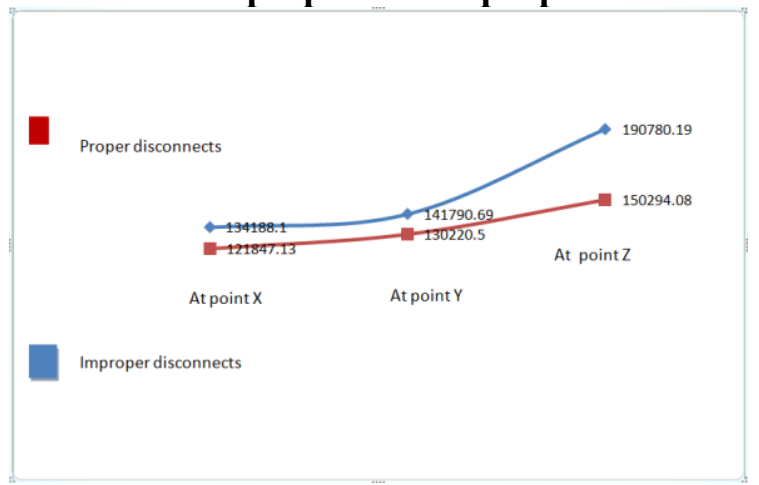

Fig. 5: EENS for $5000 \mathrm{KW}$ for proper and improper disconnects at junctions

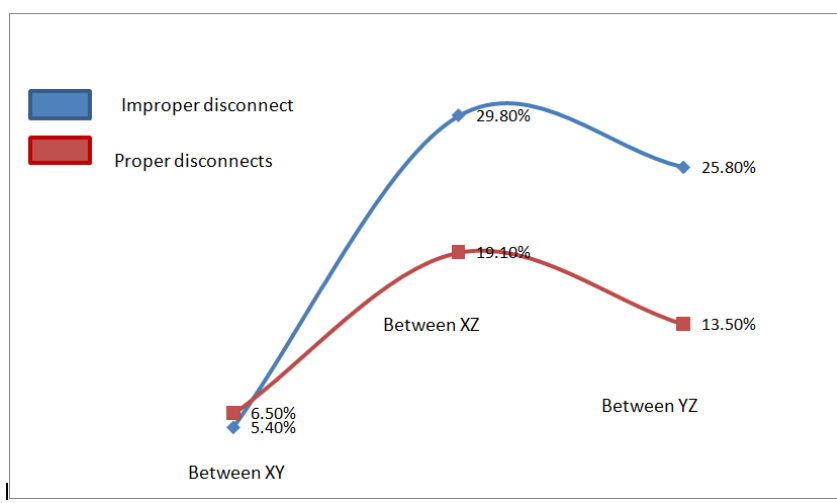

Fig. 6: SAIDI improvement in \% for $5000 \mathrm{KW}$ for improper and proper disconnects

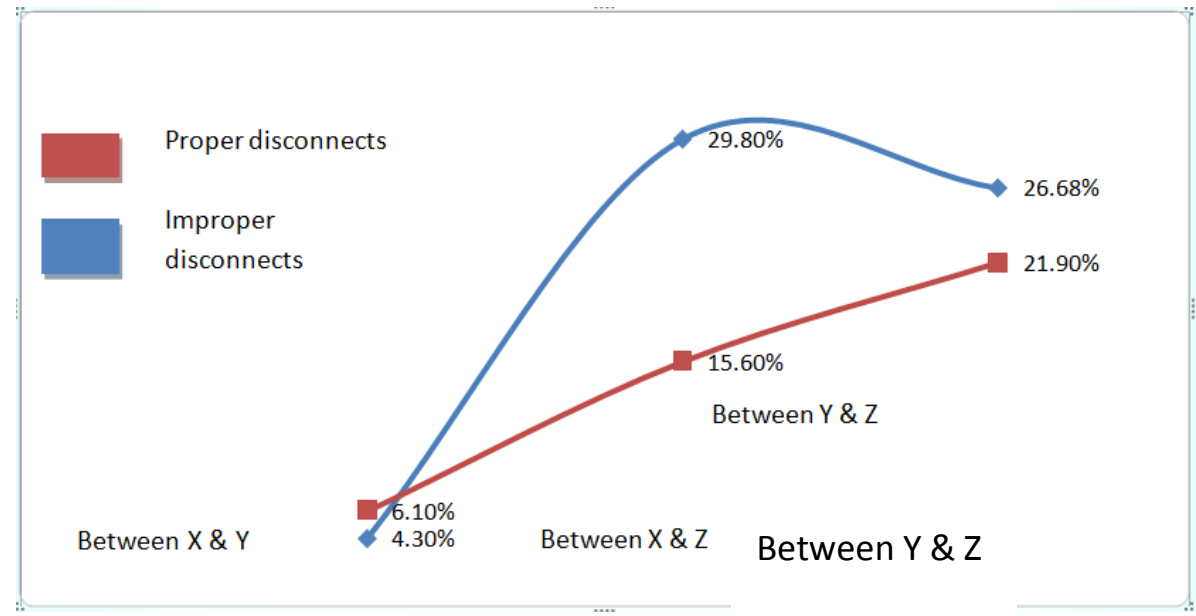

Fig. 7: CAIDI improvement in \% for $5000 \mathrm{KW}$ for proper ana improper disconnect 


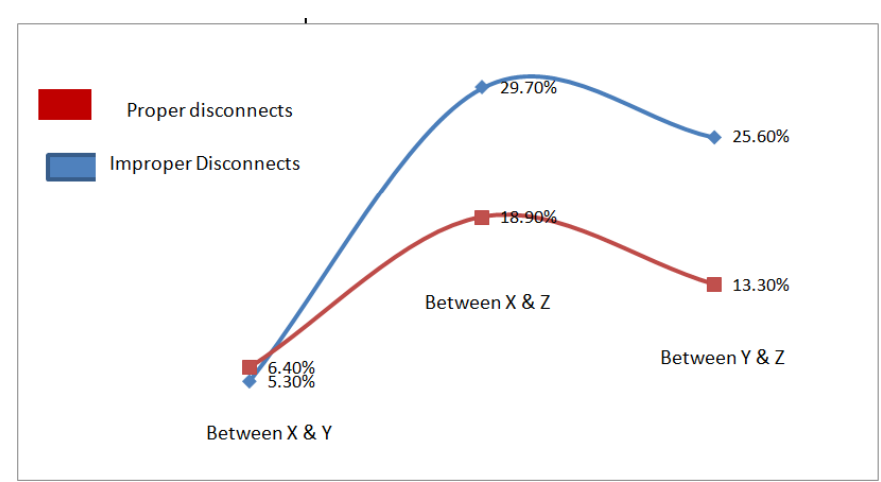

Fig. 8: EENS improvement in \% for $5000 \mathrm{KW}$ for proper and improper disconnects

Table 1: Length of sections

\begin{tabular}{|l|c|l|c|l|c|}
\hline Section & Length & Section & Length & Section & Length \\
\hline 1 & $180 \mathrm{~m}$ & 9 & $300 \mathrm{~m}$ & 17 & $400 \mathrm{~m}$ \\
\hline 2 & $150 \mathrm{~m}$ & 10 & $50 \mathrm{~m}$ & 18 & $30 \mathrm{~m}$ \\
\hline 3 & $50 \mathrm{~m}$ & 11 & $30 \mathrm{~m}$ & 19 & $50 \mathrm{~m}$ \\
\hline 4 & $40 \mathrm{~m}$ & 12 & $50 \mathrm{~m}$ & 20 & $30 \mathrm{~m}$ \\
\hline 5 & $50 \mathrm{~m}$ & 13 & $40 \mathrm{~m}$ & 21 & $1000 \mathrm{~m}$ \\
\hline 6 & $300 \mathrm{~m}$ & 14 & $300 \mathrm{~m}$ & 22 & $25 \mathrm{~m}$ \\
\hline 7 & $40 \mathrm{~m}$ & 15 & $150 \mathrm{~m}$ & 23 & $500 \mathrm{~m}$ \\
\hline 8 & $350 \mathrm{~m}$ & 16 & $50 \mathrm{~m}$ & -------- & \\
\hline
\end{tabular}

Table 2: Failure rate of laterals

\begin{tabular}{|c|c|c|c|}
\hline Lateral & Failure rate & Lateral & Failure rate \\
\hline $\mathrm{a}$ & 4 & $\mathrm{l}$ & 2 \\
\hline $\mathrm{b}$ & 2 & $\mathrm{~m}$ & 3 \\
\hline $\mathrm{c}$ & 3 & $\mathrm{o}$ & 4 \\
\hline $\mathrm{d}$ & 4 & $\mathrm{p}$ & 3 \\
\hline $\mathrm{e}$ & 3 & $\mathrm{q}$ & 2 \\
\hline $\mathrm{f}$ & 2 & $\mathrm{r}$ & 3 \\
\hline $\mathrm{g}$ & 1 & $\mathrm{~s}$ & 4 \\
\hline $\mathrm{h}$ & 4 & $\mathrm{t}$ & 3 \\
\hline $\mathrm{i}$ & 3 & $\mathrm{u}$ & 1 \\
\hline $\mathrm{j}$ & 4 & $\mathrm{v}$ & 4 \\
\hline $\mathrm{k}$ & 3 & & 3 \\
\hline
\end{tabular}

Table 3: Load point capacity

\begin{tabular}{|c|c|c|c|c|c|}
\hline $\begin{array}{l}\text { LOAD } \\
\text { POINTS }\end{array}$ & $\begin{array}{l}\text { LOAD IN } \\
\text { KW }\end{array}$ & $\begin{array}{l}\text { NO OF } \\
\text { CUSTOMER }\end{array}$ & $\begin{array}{l}\text { LOAD } \\
\text { POINTS }\end{array}$ & $\begin{array}{l}\text { LOAD IN } \\
\text { KW }\end{array}$ & $\begin{array}{l}\text { NO OF } \\
\text { CUSTOMER }\end{array}$ \\
\hline A & 190 & 95 & $\mathrm{~L}$ & 300 & 135 \\
\hline $\mathrm{B}$ & 238 & 110 & $\mathrm{M}$ & 238 & 110 \\
\hline $\mathrm{C}$ & 238 & 110 & $\mathrm{~N}$ & 238 & 110 \\
\hline $\mathrm{D}$ & 238 & 110 & $\mathrm{O}$ & 95 & 45 \\
\hline $\mathrm{E}$ & 238 & 110 & $\mathrm{P}$ & 238 & 110 \\
\hline $\mathrm{F}$ & 60 & 30 & $\mathrm{Q}$ & 60 & 30 \\
\hline $\mathrm{G}$ & 238 & 110 & $\mathrm{R}$ & 95 & 45 \\
\hline $\mathrm{H}$ & 24 & 01 & $\mathrm{~S}$ & 238 & 110 \\
\hline $\mathrm{I}$ & 238 & 110 & $\mathrm{~T}$ & 455 & 190 \\
\hline $\mathrm{J}$ & 238 & 110 & $\mathrm{U}$ & 95 & 45 \\
\hline
\end{tabular}


Table---4

\begin{tabular}{|c|c|c|c|c|c|c|}
\hline \multirow[b]{2}{*}{$\begin{array}{l}\text { Reliability } \\
\text { Indices }\end{array}$} & \multicolumn{3}{|c|}{ Improper Junction } & \multicolumn{3}{|c|}{ Proper Junction } \\
\hline & $\begin{array}{l}\text { Location } \\
\text { X }\end{array}$ & $\begin{array}{c}\text { Location } \\
\mathrm{Y}\end{array}$ & $\begin{array}{c}\text { Location } \\
\text { Z }\end{array}$ & $\begin{array}{l}\text { Location } \\
\text { X }\end{array}$ & $\begin{array}{c}\text { Location } \\
\mathrm{Y}\end{array}$ & $\begin{array}{c}\text { Location } \\
\text { Z }\end{array}$ \\
\hline SAIFI & $\begin{array}{l}25.93 \\
\text { Intr/cust.yr }\end{array}$ & $\begin{array}{l}25.93 \\
\text { Intr/cust.yr }\end{array}$ & $\begin{array}{l}25.93 \\
\text { Intr/cust.yr }\end{array}$ & $\begin{array}{l}25.93 \\
\text { Intr/cust.yr }\end{array}$ & $\begin{array}{l}25.93 \\
\text { Intr/cust.yr }\end{array}$ & $\begin{array}{l}25.93 \\
\text { Intr/cust.yr }\end{array}$ \\
\hline SAIDI & $\begin{array}{l}1701.2 \\
\mathrm{~min} / \text { cust.yr }\end{array}$ & $\begin{array}{l}1798.7 \\
\text { min/cust.yr }\end{array}$ & $\begin{array}{l}2426.8 \\
\mathrm{~min} / \text { cust.yr }\end{array}$ & $\begin{array}{l}1544.7 \\
\mathrm{~min} / \text { cust.yr }\end{array}$ & $\begin{array}{l}1652.2 \\
\mathrm{~min} / \text { cust.yr }\end{array}$ & $\begin{array}{l}1909.4 \\
\text { min/cust.yr }\end{array}$ \\
\hline CAIDI & $\begin{array}{c}66 \\
\mathrm{~min} / \text { cust.int }\end{array}$ & $\begin{array}{c}69 \\
\mathrm{~min} / \text { cust.int }\end{array}$ & $\begin{array}{c}94 \\
\mathrm{~min} / \text { cust.int }\end{array}$ & $\begin{array}{c}60 \\
\mathrm{~min} / \text { cust.int }\end{array}$ & $\begin{array}{c}64 \\
\mathrm{~min} / \text { cust.int }\end{array}$ & $\begin{array}{c}74 \\
\mathrm{~min} / \text { cust.int }\end{array}$ \\
\hline ASAI & 0.996763 & 0.99656 & 0.99542 & 0.99706 & 0.99686 & 0.99642 \\
\hline ASUI & 0.003237 & 0.003422 & 0.00458 & 0.002935 & 0.003139 & 0.003584 \\
\hline EENS & $\begin{array}{l}134188.1 \\
\text { Kwh/yr }\end{array}$ & $\begin{array}{l}141790.69 \\
\text { Kwh/yr }\end{array}$ & $\begin{array}{l}190780.19 \\
\text { Kwh/yr }\end{array}$ & $\begin{array}{l}121847.13 \\
\mathrm{Kwh} / \mathrm{yr}\end{array}$ & $\begin{array}{l}130220.5 \\
\text { Kwh/yr }\end{array}$ & $\begin{array}{l}150294.08 \\
\text { Kwh/yr }\end{array}$ \\
\hline AENS & $\begin{array}{l}62.2394 \\
\text { Kwh/cust.yr }\end{array}$ & $\begin{array}{l}65.76 \\
\text { Kwh/cust.yr }\end{array}$ & $\begin{array}{c}88.488 \\
\text { Kwh/cust.yr }\end{array}$ & $\begin{array}{l}56.5153 \\
\text { Kwh/cust.yr }\end{array}$ & $\begin{array}{l}60.399 \\
\text { Kwh/cust.yr }\end{array}$ & $\begin{array}{l}69.71 \\
\text { Kwh/cust.yr }\end{array}$ \\
\hline
\end{tabular}

